Department of Public Health Policy and Administration,

School of Public Health, University of Michigan, Ann Arbor, Michigan

K E Warner

Advocacy Institute, Washington, DC

J Butler

M Pertschuk

L Ryden

Cancer Control and

Epidemiology,

Roswell Park

Cancer Institute,

Buffalo, New York

K M Cummings

University of

California, Berkeley,

California

C D'Onofrio

Michigan Department of Public Health, Lansing, Michigan

R M Davis

Prevention Research

Center, Chicago,

Illinois

B Flay

Health Resources and

Services

Administration

Bureau of Health

Resources

Development,

Rockville, Maryland

M McKinney

Asbill, Junkin and

Myers, Chtd, and the

Coalition on Smoking

or Health,

Washington, DC

M L Myers

Fox Chase Cancer

Center, Cheltenham,

Pennsylvania

R G Robinson

University of

California, San Diego,

California

M Schudson

Stop Teenage

Addiction to Tobacco,

Springfield,

Massachusetts

J Tye

Division of

Advertising Practices,

Federal Trade

Commission,

Washington, DC

J Wilkenfeld

Correspondence to:

Professor Kenneth E

Professor Kenneth E

Public Health Policy and

Public Health Policy and
Administration, School of

Administration, School of
Public Health, University of

Michigan, 1420 Washington

Heights, Ann Arbor,

Michigan 48109-2029, USA.

\title{
Report of the Tobacco Policy Research Study Group on Tobacco Marketing and Promotion
}

Kenneth E Warner, Judy Butler, K Michael Cummings, Carol D'Onofrio, Ronald M Davis, Brian Flay, Martha McKinney, Matthew L Myers, Michael Pertschuk, Robert G Robinson, Linda Ryden, Michael Schudson Joe Tye, Judith Wilkenfeld

In this report a distinction is drawn between two categories of marketing and promotion activities. The first and most familiar category includes activities typically denoted by "advertising and promotion", entailing tobacco company efforts targeted directly at tobacco consumers or prospective consumers and intended to encourage tobacco use (either initiation or maintenance, and either brand specific or brand neutral smoking).

The second category of activities consists of tobacco companies' promotion efforts directed at groups of people or influential individuals and intended to promote a social and political environment more supportive of, or less hostile toward, tobacco consumption and marketing. This includes a wide range of organisational support from industry - example, to the arts, charities, and political organisations - "public interest" advertising, and political (financial) support of legislators. ${ }^{1}$

The distinction between these two categories is not rigid. For example, tobacco company sponsorship of sporting events serves both purposes - direct advertising to consumers and potential consumers, and the development of institutional "loyalty" to the tobacco industry - with the anticipated political ramifications such support may produce. Nevertheless, most marketing and promotion activities by industry can be readily differentiated. Because the working group deemed the "environmental support" activities to be fundamentally different from direct to consumer advertising and promotion, and because each category is believed to be critically important, the working group agreed that it would consider only direct to consumer advertising and promotion in this report. A review of knowledge and policy research needs related to "environmental support" promotional activities was undertaken by a separate task force (Study Group on Marketing and Promotions Targeted at African Americans, Latinos, and Women); their conclusions are contained in a separate paper in this supplement (p S24).

\section{Background}

Two recent major publications have reviewed the evidence pertaining to the effects of cigarette advertising and promotion, as well as the impacts of related policy measures. Part of the 1989 Surgeon General's report, Reducing the Health Consequences of Smoking: 25 Years of Progress, examined the evidence on the effects of advertising in some detail. ${ }^{2}$ New Zealand's Toxic Substances Review Board also produced a report noteworthy for its thorough review and analysis of the world publications pertaining to the impacts of advertising restriction policies. ${ }^{3}$

Given their recent date and the extent and depth of evidence and analysis in these documents, this report will not unnecessarily duplicate these efforts. Rather, readers are referred to these publications with this report offering a brief summary of findings derived from the publications that the working group believes to be of critical importance. Although much knowledge about advertising derives from studies in other countries, we will focus exclusively on the impact of advertising and promotion in the United States.

We begin by emphasising the irony that cigarettes are simultaneously the source of more death and disability than any product ever invented, yet they are also the object of the largest marketing effort devoted to any product in the United States. In 1989, the tobacco industry spent $\$ 3.62$ billion on cigarette advertising and promotion. ${ }^{4}$

Published studies offer substantial evidence that advertising and promotion influence the aggregate quantity of tobacco consumed and the number of people using tobacco products, particularly cigarettes. Nevertheless, it is critical to emphasise that the issue is not whether advertising and other promotional techniques play the major part in enticing non-smokers, especially children, to begin using tobacco. Rather, the issue is whether advertising plays any part in encouraging consumption, and if so, what is its nature and its importance.

This distinction deserves emphasis because the tobacco industry and sections of the advertising industries have attempted to obfuscate the issues involved through recourse to two arguments.

One - the "brand share" argument propounds that the only functions of cigarette advertising are to maintain brand loyalty and to encourage brand switching among established smokers. The two industries claim, disingenuously, that these are the only functions of advertising in what they refer to but seldom define as " mature markets'. They have successfully distorted the dialogue by repeat- 
edly obliging public health advocates to argue that, to the contrary, "the" function of advertising is to encourage new and expanded consumption, particularly among new consumers - ovewhelmingly children - in countries like the United States. A review of the evidence leads to the strong conclusion that neither position is tenable alone: brand share is not the sole function of cigarette advertising; and market expansion is not necessarily its main function. The evidence supports the proposition that advertising serves both functions - brand share and market expansionwith their comparative importance being incompletely understood.

The industries' second argument is that numerous factors are more influential than advertising in children's decisions to smoke or to use smokeless tobacco products. Typically cited are the influences of parents, peers, and role models, and various psychological factors. The health community's response to this proposition has often been overdefensive, attempting to emphasise the importance of advertising in this constellation of influences. Although the evidence supports the position that these other influences are more important than advertising, it does not follow from this that the influence of advertising is unimportant. Most importantly though, unlike these other influences, advertising is a policy tractable influence on tobacco consumption. Parental example, peer influence, and prevailing cultural norms about smoking cannot be subject to legislative change in the direct way that advertising and promotional influences can be.

The evidence reviewed in the aforementioned publications ${ }^{2,3}$ strongly indicates that advertising and promotion do constitute a significant influence on cigarette consumption, although the extent of the influence and the precise mechanisms by which it operates are not fully elucidated by existing research. These deficiencies are obviously major tasks for future research. As the Surgeon General warns, it may be difficult to isolate the precise effects of advertising, ${ }^{2}$ but these difficulties should not inhibit those involved in research and policy from developing and implementing rational policies and further research.

As a component of that research, there is a need to consider the multiple mechanisms by which advertising can influence cigarette consumption. Of greatest public concern is the possibility that the seductive imagery of advertising entices children to start using tobacco, thereby leading to early addiction; but other mechanisms, both direct and indirect, may be at work as well. It is crucial that the research community attempts to differentiate and elucidate these distinctive mechanisms, each of which may represent a means by which advertising might increase cigarette consumption. ${ }^{5}$

Specifically, the direct mechanisms, as well as the seduction of children, include the following:

- Advertising may reduce the resolve of current smokers to stop or to consider stop- ping, either by reinforcing imagery or by convincing the potential stopper that there are viable and "easier" alternatives. In this context, advertisements for low tar and nicotine cigarettes, argued by the industry to represent prototypical "brand share" advertising, may have aggregate consumption increasing effects, dissuading smokers from trying to stop. Similarly, advertising associated with the new downward price competition in the cigarette market could provide price sensitive smokers with a viable alternative to giving up smoking. - Advertising could encourage relapse among those giving up smoking, enticing some exsmokers to resume smoking. The seductive imagery of advertisements, especially pervasive in urban environments, could break the person's resolve to remain off cigarettes.

- Advertising could increase current smokers' daily consumption of cigarettes. Advertisements could "cue" smokers to light up, thereby increasing their daily consumption from a level that might apply in the absence of such cuing. Every increase of one cigarette for the average smoker translates into more than $\$ 1$ billion in additional sales in the United States.

There are also indirect mechanisms by which advertising may influence consumption. That most discussed is an effect flowing from the media's receipt of valuable cigarette advertising revenue and, increasingly, of noncigarette advertising revenue from other products marketed by the cigarette producing conglomerates. A substantial body of evidence, both anecdotal and empirical, leads to the conclusion that media - especially magazines seeking the continuation of this revenue, have suppressed full discussion of the hazards of smoking for fear of offending tobacco companies and thereby losing the revenues. ${ }^{6-8}$ The consequence is that readers may receive a distorted view of the relative health risks attributable to various products and behaviours, and specifically that active and latent censorship of coverage of the health consequences of smoking will create the impression that smoking is less of a danger in the constellation of risk, than it is in fact. A reduced perception of smoking's hazards, it is argued, may increase the prevalence of smoking.

A second indirect mechanism is advertising's contribution to a cultural environment in which smoking is perceived to be more common, more socially acceptable, and less dangerous than it is in fact. This, too, would be expected to increase consumption compared with a less supportive environment.

A third indirect mechanism crosses the borderline between the two categories of promotion identified previously in the prologue: industry support of the arts, charities, politicians, etc, may lead influential persons and organisations to support the interests of the tobacco industry or inhibit those who would otherwise support efforts for tobacco control, thereby undermining support for policies of tobacco control designed to decrease consumption. As noted in the prologue, the 
unique elements of this indirect mechanism caused the working group to recommend that it be subject to an independent assessment.

The essential point of this enumeration of "mechanisms" is that understanding the effects of advertising and promotion on consumption can benefit from more conceptual work and empirical disaggregation. As the subsequent pages suggest, there are potentially useful research studies that could consider pieces of this puzzle, and could thereby further this process of understanding.

If more work is needed to understand the effects of advertising, the same can be said about developing further knowledge of the consequences of advertising related policies. The principal issue here is the impact of a ban on advertising, complete or partial (for example, broadcast media). This is a subject much discussed and occasionally analysed carefully. ${ }^{3}$ The tobacco industry draws on misleading analysis of several situations internationally to "show" that advertising bans do not affect total consumption (which, of course, is a necessary conclusion of the industry's basic claim about the role of advertising in the first place). ${ }^{9,10}$

Although the issue is a complex one, the New Zealand Toxic Substance Review Board's recent analysis ${ }^{3}$ presents a convincing summary of the evidence indicating that bans have effects on aggregate consumption. Beyond a total advertising ban, few advertising policy options have received much analytical attention. Although there are notable exceptions (for example, the study of the effects of counter advertising, as in the Fairness Doctrine broadcast media antismoking messages between 1967 and $1970^{11}$ ), other policy options, such as limiting advertising to the tombstone format, have received virtually no research attention to date. This is plainly a reflection of a lack of confidence that the introduction of partial or incomplete advertising bans would not be widely circumvented by recourse to a range of marketing ploys designed to overcome the intent of such restrictions.

\section{Areas of research need}

The working group found the following to be the areas of highest research need. It is important to note that these areas are not mutually exclusive and that most research projects would fall into more than one category.

\section{THE DIRECT AND INDIRECT EFFECTS OF}

\section{ADVERTISING}

Research is needed to further test and strengthen the several hypotheses about advertising's direct impact on prevalence of tobacco use as discussed previously. Particularly, research projects are needed that can provide insights into the role of advertising in:

- Recruiting new smokers

- Reducing the cessation rate among present smokers

- Increasing the relapse rate in smokers
- Increasing daily consumption

- Persuading those concerned about the health effects to switch to low tar and nicotine cigarettes rather than stop

- Skewing perception of smoking prevalence, especially among young people.

The indirect effects of advertising and promotion are also of keen interest. Thus further research is needed into the effect tobacco advertising has on coverage of smoking as a health issue in media most dependent upon cigarette advertising revenues, such as racial minority, ethnic, and women's media.

\section{THE DESIGN OF ADVERTISING AND PROMOTION} CAMPAIGNS

To show the direct and indirect effects of advertising and promotion is inherently difficult. As an Australian tobacco industry executive has written: "This claim [that advertising influences aggregate demand] is particularly difficult to refute as the only true test would be to study the consumption trend in a number of different markets under conditions of full cigarette advertising and no cigarette advertising, but over the same period as to achieve identical economical and social pressures. This is clearly impossible..."12 An important ancillary source leading to understanding the probable effects of advertising is analysis of the evident design and intent of advertising and promotion campaigns. ${ }^{13}$ For example, research into the themes and images used to promote low tar and nicotine cigarettes could be expected to give insights into implicit safety claims that may inhibit cessation. Investigations that produce evidence of the intent of a campaign such as the marketing documents for R J Reynold's proposed Dakota campaign to be targeted at the "virile female" $" 14$ are particularly useful.

\section{UNDERSTANDING TARGETED MARKETING TO} WOMEN, RACIAL AND ETHNIC MINORITIES, AND YOUNG PEOPLE

Both effects and design research are particularly needed to develop appropriate policy responses to targeted marketing. Content and audience reception research, which illuminates the evident intent of cigarette advertisers to exploit ethnic, racial, and cultural vulnerabilities, can be useful in enabling community leaders to mobilise community opposition to such practices, and to generate community support for policies restricting advertising and promotion generally. The successful campaign against Uptown advertising and promotion showed that targeted communities deeply resent such "outside" manipulation. ${ }^{15}$

Research is also needed on the relation of target marketing to variations in smoking patterns within target populations. For example, what part does targeted advertising play in the striking preference of African Americans for menthol cigarettes? Does such advertising contribute to or exploit a prevailing belief among African American smokers that menthol cigarettes are less hazardous? If so, 
should specific countervailing warnings be advocated?

Studies that disclose an increased prevalence of smoking among targeted populations (for example, among teenage girls in Japan and Korea $^{16}$ ) after the introduction of targeted brands and advertising campaigns are useful in showing the impact of advertising on prevalence within targeted populations. Such research would arm the leaders of newly targeted populations in the US, such as Hispanic or Asian women, to resist such targeting.

A subsidiary research question is this: Does targeted advertising play a part in promoting the high smoking rate of adult African Americans as opposed to the low smoking rate among African American children and teenagers compared with their white counterparts? If so, how? The targeting of women is an area of primary concern. "Niche" targeting, ranging from brands like Virginia Slims apparently targeted at women with a feminist consciousness, to brands targeted at working women, such as Dakota, ${ }^{14}$ merit study. To what extent, for example, was Virginia Slims advertising and promotion designed to deflect the emergence of the natural concern of women's groups at target marketing? Are other brands successful in exploiting the psychological needs of poorer working women?

The tobacco industry claims that it does not target young people. Yet many critics believe that efforts such as the "Joe Camel" campaign ${ }^{17}$ are deliberately targeted at the young. Research to plumb the impact of such campaigns on children and young people's attitudes and behaviour can provide important evidence in showing the needs for banning or severely restricting advertising.

Research projects investigating targeting in less developed countries may be particularly rewarding. The companies are often less restrained by public concern in such countries, ${ }^{18}$ and the impact of such advertising and promotion may be more readily shown. Target marketing of women in parts of Asia, for example, where currently very small percentages of women smoke, could produce special insights into the impact of target marketing on smoking prevalence.

THE IMPACT AND EFFECTIVENESS OF ADVERTISING AND PROMOTION BANS

The tobacco industry has promoted disinformation and distorted research data on the supposed ineffectiveness of advertising bans. Although much of this disinformation has been effectively unmasked, there remains a need for research on the precise effects of advertising bans. Here, too, an opportunity exists in less developed countries and others that adopt advertising bans, for prospective studies, taking baseline data before the implementation of bans and charting the subsequent prevalence of smoking. Comparative studies of teenage knowledge and attitudes toward smoking in jurisdictions with and without advertising bans could provide insight into the effects of such bans.
A need for research also exists into the creative strategies by the tobacco companies to thwart advertising bans and restrictions, such as the development of marketing campaigns for non-tobacco products and services bearing cigarette brand names ("brand stretching"). Such research could assist policy makers to design loophole-proof laws and regulations.

Of great potential help to policy advocates would be case studies of effective and ineffective campaigns designed to influence public and political opinion against tobacco advertising. Such studies might help to answer such strategic questions as: What coalition formation and nurturance is required to ensure the success of such campaigns? What issue framing strategies are most influential with policy makers? Which lobbying techniques are effective and which are counterproductive?

\section{EVALUATION OF TOBACCO INDUSTRY SELF} REGULATION

In many countries, the tobacco industry has deflected advertising ban initiatives by vowing adherence to self regulatory advertising codes. Research into both the design and implementation of such codes would help in understanding their limitations. For examples, studies that examined the impact of limiting the age of models to 25 and older on perceptions about the attractiveness and desirability of smoking among teenagers would be useful in considering claims by reluctant regulators that such provisions fulfilled their stated intent. Similarly, studies that document the extent of the common lack of enforcement of even weak industry codes would be useful in answering industry arguments that enforced policies are unnecessary.

\section{PUBLIC OPINION RESEARCH RELATED TO}

ADVERTISING POLICIES

Policy makers are influenced by public attitudes towards proposed policies. Policy makers are likely to be influenced by such studies as those:

- that show high levels of citizen disapproval of cigarette advertising and promotion (including such specific campaigns as the Camel "Smooth Character")

- that find little support for a tobacco industry's "right to advertise" (which indicates that majorities do not consider advertising a form of speech worthy of the same protection afforded political and artistic expression)

- that indicate that most people believe that advertising increases consumption (especially that it entices young people to start smoking) - that indicate broad popular support for advertising bans and other restrictive measures.

\section{Summary}

Advertising and promotion to the consumer have a central role in sustaining use of tobacco. In particular, they are critical to luring new, 
young customers to smoking. Although they are not the sole reason that young people begin smoking, they are clearly the most policy tractable. Furthermore, advertising and promotion are among the most important mechanisms by which the tobacco industry targets particularly vulnerable segments of the population, such as women, to smoke. Given their direct and indirect effects, advertising and promotion are among the most important issues to be considered by tobacco control policy research.

1 Begay ME, Glantz SA. Undoing proposition 99: political expenditures by the tobacco industry in California politics in
1991 . Institute for Health Policy Studies, School of Medicine, University of California, April 1992.

2 US Department of Health and Human Services. Reducing the health consequences of smoking : 25 years of progress. A the health consequences of smoking: 25 years of progress. A report of the Surgeon General. US Department of Health and Human Services, Public Health Service, Centers for Disease Control, Center for Chronic Disease Prevention
and Health Promotion, Office on Smoking and Health. and Health Promotion, Office on Smoking and Health. (DHHS Publication No (CDC) 89-8411.)

3 Toxic Substances Board. Health or tobacco: an end to tobacco advertising and promotion. Wellington, New Zealand: Toxic Substances Board, 1989.

4 Federal Trade Commission report for 1989, Persuant to the Federal Cigarette Labeling and Advertising Act. Tobacco Control 1992; 1: 73-7.

5 Warner K. Selling smoke: cigarette advertising and public health. Washington, DC: American Public Health Association, 1986 .

6 Warner KE, Goldenhar LM, McLaughlin CG. Cigarette advertising and magazine coverage of the hazards of smoking: a statistical analysis. New Engl f Med 1992; 326: 305-9.

7 Minkler M, Wallack L, Madden P. Alcohol and cigarette advertising in MS. Magazine. $f$ Public Health Policy 1987; Summer: 164-79.

8 Whelan EM et al. Analysis of coverage of tobacco hazards in women's magazines. $f$ Public Health Policy 1981; Mar: in wom.

9 Boddewyn JJ, ed. Tobacco advertising bans and consumption in 16 countries. New York: International Advertising Association, 1986

10 Boddewyn JJ, ed. Why do juveniles start smoking? New York: International Advertising Association, 1987.

11 Doron G. The smoking paradox. Public regulation in the cigarette industry. Cambridge, Massachusetts: Abt, 1979

12 Ryan WP (Rothmans Australia). Cigarette advertising - it role and rationale. Paper presented to Health Advisory Council, Health Commission of New South Wales, 1978 July 17.

13 Chapman S. Great expectorations: advertising and the tobacco industry. London: Comedia, 1986.

14 Specter M. Marketers target 'virile female'. Rf Reynolds plans to introduce cigarette. Washington Post $1990 \mathrm{Feb}$ plans 17 .

15 Robinson RG, Pertschuk M, Sutton C. Smoking and African Americans: spotlighting the effects of smoking African Americans: spotlighting the effects of smoking
and tobacco promotion in the African American community. In: Samuels SE, Smith MD, eds. Improving the munity. In: Samuels SE, Smith MD, eds. Improving the
health of the poor, strategies for prevention. Menlo Park, California: Henry J Kaiser Family Foundation, 1992.

16 Hong Y, Kim S, Kwon D. Surveys on the smoking habits in Korea. Proceedings of the 2nd Asia-Pacific Conference on Tobacco or Health. Seoul: Korean Association of Smoking and Health, 1992.

17 Fischer PM, Schwartz MP, Richards JW, Goldstein AO, Rojas TH. Brand logo recognition by children aged 3 to 6 years. Mickey Mouse and Old Joe the Camel. fAMA 1991; 266: 3145-8.

18 Chapman S, Wong WL. Tobacco control in the Third World. $A$ resource atlas. Penang: International Organization of Consumers Unions, 1990. 